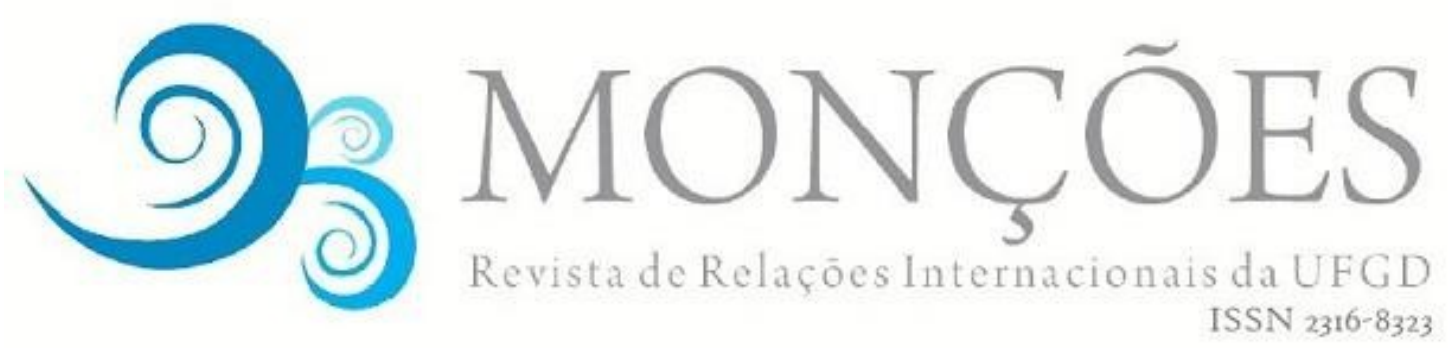

\title{
ALGUMAS CONSIDERAÇÕES SOBRE A ESQUEMÁTICA DE PODER EM NYE E O PENSAMENTO DE ANTONIO GRAMSCI ${ }^{1}$
}

FRIEDRICH MAIER

Graduação em Relações Internacionais e Mestrando em Ciências Sociais pela Universidade Estadual

Paulista "Julio de Mesquita Filho" - Faculdade de Filosofia e Ciências de Marília (UNESP / FFCMarília). Orientador: Prof. Dr. Rodrigo Duarte Fernandes dos Passos. Contato: fmaier250@gmail.com

RESUMO: O poder brando (soft power) e o poder duro (hard power) possuem ampla ressonância dentro do campo de estudo das relações internacionais, figurando enquanto conceitos cristalizados na mídia, declarações oficiais e análises de política exterior. O seguinte trabalho se propõe a analisar esses conceitos apontando relação com a categoria de hegemonia de Antonio Gramsci e, a partir de tal relação, infere algumas críticas metodológicas. A tentativa de Nye, de separar o centauro maquiavélico recuperado por Gramsci, revela falhas dentro da esquemática de poder desse importante autor da corrente liberal das relações internacionais.

PALAVRAS-CHAVE: Poder brando, Poder duro, Hegemonia.

\section{SOME NOTES ON NYE'S SCHEME OF POWER AND THE THOUGHT OF ANTONIO GRAMSCI}

\begin{abstract}
Soft and hard power are concepts with high relevance on international relations field of study, appearing like "crystalized concepts" on media, official statements and foreign policy reviews. The following paper aims to analyze these concepts and to point a relation with Gramsci's concept of "hegemony". Then, we draw some critics about methodological issues. Nye's attempt of detach the Machiavellian centaur recovered by Gramsci reveals some fails inside the theory of this important author from liberal school of international relations.
\end{abstract}

KEY-WORDS: Soft power, Hard power, Hegemony.

\section{Introdução}

Joseph S. Nye Jr é um dos teóricos mais reconhecidos dentro do campo de estudos das Relações Internacionais. Seus trabalhos versam sobre questões como

\footnotetext{
${ }^{1}$ Uma versão anterior desse texto foi apresentada na "I Jornada Internacional de Estudos e Pesquisas em Antonio Gramsci", em Fortaleza-CE, dias 23 à 25 de novembro de 2016. Além disso, agradeço aos pertinentes e enriquecedores comentários dos pareceristas anônimos da Revista Monções que muito auxiliaram na elaboração e ampliação do manuscrito.
} 
os efeitos da globalização, a cooperação internacional e a manutenção da liderança estadunidense a nível global. As proposições teóricas desse importante autor passaram a ganhar ressonância ainda na década de 1970, com a publicação de "Power and Interdependence", em coautoria com o professor também estadunidense Robert O. Keohane, no qual o conceito de interdependência complexa é cunhado: uma espécie de relação entre os Estados dentro do sistema internacional que envolve custos, elevando a complexidade de atuação em âmbito global.

Todavia, é em 1990 com o livro "Bound to Lead" (NYE Jr, 1990) que Nye proporá uma nova terminologia para tratar do conceito, muito em voga nas relações internacionais, de poder. $O$ autor afirma uma concepção de poder que leva em conta não somente os recursos materiais do mesmo (população, território, PIB, forças armadas) mas também uma espécie de poder comportamental, isto é, o comportamento por detrás dos empregos das diversas fontes de poder. Surgem então, os conceitos de poder brando (soft power) e poder duro (hard power) que atualmente são amplamente utilizados dentro desse promissor campo de estudos ${ }^{2}$.

A partir de um mapeamento conceitual que passou pelas principais obras teóricas do autor sub examine, identifico em conjunto com outros comentadores algumas questões de caráter metodológico e teórico que apontam para certas imprecisões. Além disso, identifico também dentre os conceitos cristalizados do autor uma relação muito intensa com algumas das proposições gramscianas para a categoria de hegemonia.

Desse modo, proponho responder a seguinte pergunta: A partir da leitura em extensão das obras de maior volume teórico de Joseph S. Nye Jr (NYE Jr, 1990, $2002,2004,2011,2015)$ qual a sistemática de poder proposta pelo autor e de que

\footnotetext{
2 A página de compilação de citações "Google Scholar" (<scholar.google.com.br>) aponta 63.771 citações ao autor em 17/10/2017. Destas, 27.823 concentram-se nos anos a partir de 2012. Os conceitos propostos por Nye Jr são mobilizados em análises de política externa que contemplam temáticas como a ascendência chinesa e sua utilização do soft power (KURLANTZICK, 2007; GILL, HUANG, 2006), a alteração no padrão da diplomacia pública (MELISSEN, 2005), as estratégias de expansão midiática (MARTEL, 2013), os jogos olímpicos como elemento de soft power (MANZENREITER, 2010), o papel de Bollywood para a política externa da Índia (THUSSU, 2013) e até mesmo a influência de "atores transnacionais religiosos" e seu soft power (HAYNES, 2016). Além disso, os últimos anos apresentaram grande volume de produção, em monografias de graduação e dissertações de mestrado. Citando algumas: Disney e s soft power (LO PRETE, 2016), música e soft power (MARTINS, 2016; MIRANDA, 2016), indústria cervejeira e soft power (GOUVEIA, 2015), Brasil e soft power (CALLEGARI, 2011).
} 
modo essa se relaciona com a categoria gramsciana de hegemonia? Minhas principais hipóteses apontam: a) a esquemática do autor padece de algumas imprecisões e falhas metodológicas cuja raiz se encontra numa apropriação incompleta dos pressupostos gramscianos, a saber, Nye realiza uma divisão arbitrária entre poder brando e poder duro (o consenso e a coerção do comunista sardo) sem indicação de pontos teóricos capazes de sustentar tal separação; b) há uma crucial diferença epistemológica entre os autores, se em Gramsci a filosofia da práxis tem por definição uma relação intensa em atuar sobre a realidade, em modifica-la, em Nye se identifica uma postura de aproximação entre as ciências sociais e os pressupostos das ciências naturais (positivismo), isto é, para o autor a Teoria de Relações Internacionais deveria fornecer capacidades interpretativas e de análise da realidade, sem, todavia, atuar sobre ela. Uma postura claramente conservadora, que implica numa manutenção do status quo e, portanto, diametralmente oposta àquela gramsciana.

Para fornecer a resposta para tal pergunta e comprovar ou não essas hipóteses, lanço mão das seções a seguir, de modo que a segunda seção demonstra a sistemática de poder proposta por Nye, apontando para as peculiaridades da mesma. Já na terceira seção, aponto a relação entre os conceitos desse autor com a categoria gramsciana de hegemonia, perpassando outros autores que também comentam essa relação. As críticas à metodologia de Nye constarão na quarta seção. E, por fim, tecem-se algumas considerações que em nosso caso são parciais, uma vez que a pesquisa ainda se encontra longe de seu término.

\section{A esquemática de poder de Nye e seu "novo" poder}

Como já disse acima, é em Bound to Lead (1990), que Joseph S. Nye Jr lançará mão de seus argumentos que alteram a visão clássica de poder. Suas apreensões sobre o status da política internacional apontam para uma mudança, ainda que em estágios iniciais, dentro das relações internacionais. Os motivos dessa mudança abarcam uma série de fatores como a globalização, o fim do conflito entre 
EUA e URSS, o notável grau de interdependência econômica e a revolução da informação ${ }^{3}$.

Os fatores acima elencados alterariam a forma como o poder se manifesta e como os políticos devem avaliá-lo. Sob o pretexto de que as atuais teorias de relações internacionais não são capazes de compreender toda a complexidade do sistema internacional ${ }^{4}$, Nye argumentará a necessidade de uma aproximação ao conceito de poder que leva em consideração suas duas faces, uma baseada na sua característica comportamental (behavioral power) e uma baseada em suas fontes (resource power).

Dessa forma, o poder comportamental divide-se em mais duas formas: o poder de comando (command power) e o poder cooptivo (co-optive power). O poder de comando é definido sinteticamente por Nye como uma "habilidade de mudar o que os outros fazem" (NYE, 1990, p. 267, trad. livre) e se manifesta por meio da coerção ou da indução ${ }^{5}$. Já o poder cooptivo refere-se à habilidade de modificar as preferências dos outros atores, isto é, moldar o pensamento dos outros para que estes ajam de uma determinada forma (NYE Jr, 1990).

Seguindo a conceitualização do autor, cada forma de poder comportamental tem por base uma fonte de poder. Portanto, o poder de comando, por consistir principalmente em uma ação de coerção ou recompensa, relaciona-se às fontes de poder duro (hard power). Enquanto que o poder cooptivo, consistindo na atração e persuasão, relaciona-se às fontes de poder brando (soft power). $O$ autor lança mão de ressalva, afirmando a inexatidão dessa relação, demonstrando a possibilidade de

\footnotetext{
${ }^{3}$ A revolução da informação refere-se para Nye aos rápidos avanços científicos em tecnologias de comunicação que diminuem drasticamente os custos de produção, transmissão e processamento da informação. Esse processo tem notável caráter transformador para as relações internacionais, uma vez que tende a aumentar a complexidade de ação estatal ao promover a difusão do poder, a emergência da importância do poder brando e requerer a alteração do comportamento dos Estados Unidos da América em suas relações internacionais. Para mais informações ver: NYE Jr, 1998; 2002; 2004; 2010, 2015.

${ }^{4}$ Nye mantém uma postura de diálogo com os autores ditos "realistas", isto é, não descarta todos os seus pressupostos, mas apresenta uma série de correções. Como podemos ver em: "A resposta apropriada para as mudanças que ocorrem na política mundial não é desacreditar a sabedoria tradicional do realismo e sua preocupação com o equilíbrio de poder militar, mas a perceber suas limitações e completá-la com ideias da abordagem liberal." (NYE, 1990, p. 178, tradução livre).

${ }^{5}$ Para simplificar a explicação, o autor utiliza a popular expressão em inglês "sticks and carrots" (paus e cenouras) para referir-se aos modos de se obter poder de comando, numa aproximação, essa expressão significa uma combinação de punição (militar) e recompensa (econômica). Ver: NYE Jr, 1990.
} 
relação entre o poder de comando e as fontes de poder brando em alguns casos, da mesma forma que o poder cooptivo pode se relacionar às fontes de poder duro. Todavia, afirma que a relação principal manifesta-se forte o suficiente para que haja a associação entre poder de comando e o poder duro e entre poder cooptivo e o poder brando (NYE, 1990; 2004).

Apesar da distinção elaborada acima, encontramos em textos posteriores do autor (NYE Jr, 2012; 2015) a utilização indistinta do conceito de "poder brando" para tratar ao mesmo tempo da face comportamental e da face de recursos do poder, isto é, Nye utiliza do conceito de "poder brando" enquanto sinônimo de "poder cooptivo" (face comportamental) e de "poder brando" (fonte de poder). O mesmo aplica-se para o conceito de "poder duro", utilizado tanto como "poder de comando" (face comportamental) e "poder duro" (fonte de poder). Importante destacar também que em obras mais recentes do autor (NYE Jr, 2012) os conceitos de "poder duro" e "poder brando" são utilizados em conjunto com outros conceitos, como "poder militar" e "poder econômico". Podemos compreender enfim, numa síntese da sistemática mais atual, que poder brando e poder duro referem-se à face comportamental do emprego dos diversos recursos de poder (econômico, militar, brando $^{6}$ ) por um determinado ator ${ }^{7}$. A figura a seguir representa as mudanças nos conceitos:

Figura 1: As esquemáticas atuais do poder em Nye Jr.

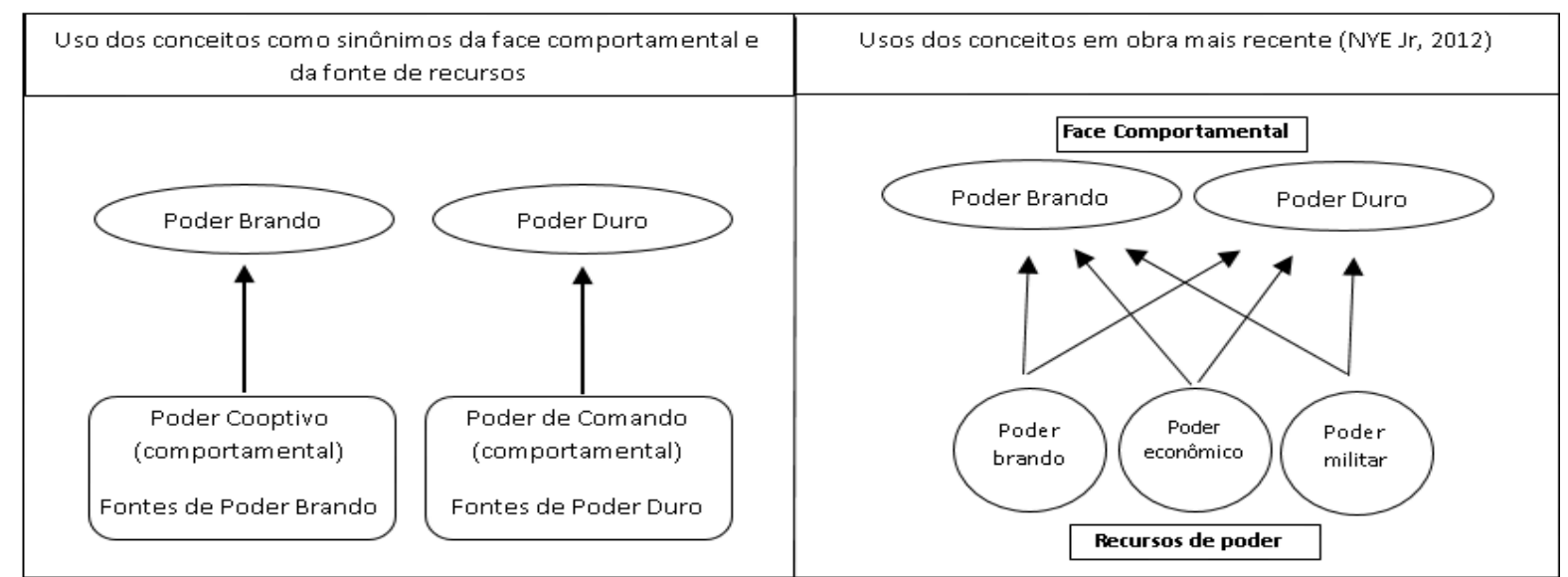

\footnotetext{
${ }_{7}^{6}$ Nesse caso, refere-se às fontes de poder brando.

${ }^{7}$ Isso significa que cada análise deve levar em conta as fontes de recurso de poder e de que modo foram empregadas a fim de constatar a existência de poder brando ou poder duro em termos comportamentais.
} 
Fonte: NYE Jr (2004; 2012). Elaboração própria

A partir do discutido, compreende-se o poder duro enquanto a manifestação tradicional do poder "realista", compreendendo uma série de fatos que vão desde o embate direto em uma guerra até as chantagens econômicas por meio de sanções e/ou incentivos tributários. Os recursos (fontes) desse tipo de comportamento de poder são também os mesmos recursos apontados por autores realistas: a população, o território, a riqueza mineral e natural, a quantidade de capital, a preparação e equipagem das forças armadas, dentre outros ${ }^{8}$; Nye qualifica tais recursos como "tangíveis", afirmando o poder duro como "tangível".

O poder brando, pelo contrário, se relaciona, para um Estado, com as fontes de poder "intangíveis" como a cultura, os valores políticos e a atuação de política externa. Esses componentes manifestam-se internacionalmente e podem atuar de duas formas: uma direta e outra indireta. A primeira forma tem foco nas elites e consiste na tentativa de influenciar pessoas que posteriormente ascenderão a cargos de tomadores de decisão política (policymakers) e atuarão de modo benéfico ao Estado influenciador. O modo indireto consiste em criar dentro do Estado alvo um ambiente "capacitante" a partir da atração e persuasão do público, isto é, um ambiente favorável aos interesses do Estado influenciador, objetivando a mudança no comportamento das elites políticas via pressão popular.

O poder brando seria, assim, uma forma de atuação relativamente menos agressiva no ambiente internacional, baseado numa espécie de atração e persuasão que levam à aquiescência. Nye preconiza a necessidade de um melhor balanceamento entre o poder brando e o poder duro: seria o exercício de um "poder inteligente" (smart power) (NYE Jr, 2012; 2015) e, além disso, exorta a importância do poder brando no contexto global atual, no qual a revolução da informação tende a tornar uma parte do poder estatal difusa, ampliando os custos de ação ${ }^{9}$ em termos de poder duro (NYE Jr, 2011, 2012).

\footnotetext{
${ }^{8}$ Como, por exemplo, observamos em MORGENTHAU (2003) especialmente capítulo IX - Elementos do poder nacional (pp. 215-294), no qual se destacam como "elementos do poder nacional" tanto os recursos como geografia, alimentos, matérias-primas, capacidade industrial, grau de preparação militar (tecnologia, liderança, quantidade e qualidade das forças armadas), quanto recursos mais subjetivos, como "índole nacional", "moral nacional" e qualidade da diplomacia e do governo.

9 Os "custos de ação" remetem ao conceito de interdependência complexa, a proposição de "um mundo no qual segurança e força importam menos e países estão conectados por múltiplos
} 
Em suma, a seção teve por objetivo demonstrar, de forma simplificada, a esquemática de poder desenhada por Nye em suas obras de maior expressão. A separação em fontes e comportamentos do "monolítico poder realista", como já dito anteriormente, ganhou ampla ressonância internacional, passando a configurar como conceito cristalizado dentro das análises de política externa e inclusive na mídia em geral (NYE Jr, 2004, pp. IX-XIII). A próxima seção se debruça sobre a relação entre essa concepção e a categoria de hegemonia em Gramsci, apontando aproximações e distanciamentos.

\section{A relação entre o poder de Nye e a hegemonia de Gramsci}

Não podemos passar pela obra do autor estadunidense aqui examinado e observar suas proposições acerca do poder brando e do poder duro (militar e econômico) sem apontar considerações sobre a relação desses conceitos com a noção de hegemonia desenvolvida pelo prisioneiro de Mussolini. Cabe ressaltar que o próprio Nye reconhece as ideias de Gramsci em um de seus textos, todavia de modo simples e pouco esclarecedor, como vemos em:

O poder brando repousa sobre a capacidade de definir a agenda política de uma forma que molda as preferências dos outros. A nível pessoal, os pais sábios sabem que se eles criarem seus filhos com as crenças e valores corretos, seu poder será maior e durará mais tempo do que se eles têm contado apenas com palmadas, cortando subsídios, ou tirando as chaves do carro. Do mesmo modo, líderes políticos e pensadores como Antonio Gramsci há muito compreenderam o poder que vem do estabelecimento da agenda e definição da estrutura de um debate (NYE Jr, 2002, p. 9, tradução livre, itálico meu).

Nesse sentido, o presente trabalho dialoga com uma série de comentadores que observam semelhanças entre os conceitos de Nye e a noção de hegemonia para Gramsci. Seguirei desenvolvendo esse argumento. Para tal discutirei de modo

relacionamentos políticos e sociais" (NYE Jr, 1998, trad. livre), marcado por relações de efeito recíproco entre Estados ou entre atores de diferentes estados, que resultam em "transações internacionais" (fluxo de dinheiro, bens, pessoas e informações) cujo fator definidor são seus efeitos de custo, isto é, só há uma relação de interdependência com custos. Nesse sentido, a interdependência complexa não implica numa visão simétrica das relações internacionais e contempla a alteração do padrão de ação estatal para além do panorama "realista" (Estado como ator central e principal com atuação somente em termos de poder) contemplando a sensibilidade (grau da capacidade de adequação) e a vulnerabilidade (custo ou capacidade de adequação) das relações entre Estados, atores nacionais e transnacionais e organizações internacionais (KEOHANE, NYE Jr, 2012). 
breve o conceito de hegemonia proposto por Gramsci, adicionarei considerações de outros comentadores das obras de Nye sobre o assunto e apontarei alguns problemas que surgem nesse ponto.

A começar pela caracterização gramsciana de hegemonia observamos que esta compreende não uma separação, uma relação de independência, mas sim uma unidade orgânica entre o que o autor chama de coerção e de consenso. Central à obra, tal categoria assume diferentes sentidos em determinados contextos ${ }^{10}$. Encontramos nela a ideia utilizada por Gramsci para desnudar os mecanismos pelos quais determinadas burguesias dirigentes conseguiam obter um certo consenso das classes exploradas garantindo, e até mesmo facilitando, a sua exploração (ZAHRAN \& RAMOS, 2006). Partindo desse exemplo claro da realidade, Gramsci apontou para dois tipos de supremacia que poderiam ser atingidos por uma classe dirigente: um baseado em maior grau na coerção, a supremacia, e outro, baseado numa aceitação, num consenso ético, ideológico, educacional da sociedade diante de sua classe dirigente, a hegemonia (Idem).

É o que vemos no excerto abaixo no qual Gramsci, ao discutir a questão do Risorgimento Italiano, aponta que a supremacia de um grupo social se manifesta através da força e de uma direção política:

O critério metodológico que deve basear sua análise é este: que a supremacia de um grupo social se manifesta em dois modos, como "domínio" e como "direção intelectual e moral". Um grupo social é dominante dos grupos adversários que tende a liquidar ou a submeter também com a força armada e é dirigente dos grupos semelhantes e aliados. Um grupo social pode e deve ser dirigente antes mesmo de conquistar o poder governamental (é essa uma das condições principais do mesmo para a conquista do poder); depois, quando exercita o poder e também o tem fortemente em mãos, torna-se dominante mas deve continuar a ser também "dirigente" (GRAMSCI, 1975, Q19, § 24, p. 2010-2011, tradução livre) ${ }^{11}$

\footnotetext{
${ }^{10}$ Thomas (2013), por exemplo, propõe uma possibilidade de separação em quatro momentos que a categoria de hegemonia assume nos Quaderni: hegemonia como liderança política e social, hegemonia como projeto político, hegemonia como aparato hegemônico e hegemonia política e social do movimento dos trabalhadores.

11 Original: II criterio metodologico su cui occorre fondare il proprio esame è questo: che la supremazia di um gruppo sociale si manifesta in due modi, come "dominio" e come «direzione intellettuale e morale». Un gruppo sociale è dominante dei gruppi avversari che tende a «liquidare» 0 a sottomettere anche con la forza armata ed è dirigente dei gruppi affini e alleati. Un gruppo sociale può e anzi deve essere dirigente già prima di conquistare il potere governativo (è questa una dele condizioni principali per la stessa conquista del potere); dopo, quando esercita il potere e anche se lo tiene fortemente in pugno, diventa dominante ma deve continuare ad essere anche «dirigente».
} 
Podemos observar aqui a organicidade do pensamento gramsciano: a hegemonia não pressupõe o fim da ideia de coerção e da mesma forma, a alçada ao poder estatal - principal (mas não único) lócus da coerção - por um determinado grupo social não implica o abandono do status de "dirigente" (consenso). É justamente o balanço entre força e consenso que garantem a condição hegemônica, a possibilidade de expansão da concepção de mundo das classes dirigentes para as demais classes e grupos sociais.

Essa apreensão da unicidade das categorias carrega a própria discussão da composição do Estado para Gramsci, formado pela relação orgânica entre sociedade civil e sociedade política. Isto significa dizer que para o filósofo sardo não se pode pensar o âmbito estatal sem distinguir - metodologicamente - suas duas esferas: uma civil, composta pelos "aparelhos privados da hegemonia" como as escolas, igrejas, universidades, centros culturais e etc., e uma política, marcada pelo próprio aparelho estatal e suas instituições burocrático-repressivas. A hegemonia percorre, desse modo, tanto a burocracia estatal quanto a "capilaridade" da sociedade civil (MORTON, 2007, pp. 92-93). Gramsci evidencia tal relação ao discutir a chamada "opinião pública", apontando para o interesse de monopólio sobre os instrumentos que exercem influência sobre essa:

Aquilo que se chama "opinião pública" está estreitamente ligado com a hegemonia política, aquilo que é o ponto de contato entre a "sociedade civil" e a "sociedade política", entre o consenso e a força. [...] A opinião pública é o conteúdo político da vontade política pública que pode ser discordante: por isso existe a luta pelo monopólio dos órgãos da opinião pública: jornais, partidos, parlamento, de modo que uma só força modele a opinião e portanto a vontade política nacional, organizando os discursos em uma poeira individual e incoerente. (GRAMSCI, 1975, Q 7, § 83, pp. 914-915, tradução livre) $)^{12}$

Dessa forma, o sardo pretende dar conta da realidade que presencia: a ampliação das funções do Estado, presente, sobretudo, a partir do Novecento (LIGUORI, 2007) e passa a compreender como o Estado remete ao próprio desenvolvimento da totalidade social ${ }^{13}$. Estado, portanto, como unidade orgânica,

\footnotetext{
${ }^{12}$ Original: Ciò che si chiama "opinione pubblica» è strettamente connesso con l'egemonia politica, è cioè il punto di contatto tra la «società civile» e la «società politica», tra il consenso e la forza. [...] L'opinione pubblica è il contenuto politico della volontà politica pubblica che potrebbe essere discorde: perciò esiste la lotta per il monopolio degli organi dell'opinione pubblica: giornali, partiti, parlamento, in modo che una sola forza modelli l'opinione e quindi la volontà politica nazionale, disponendo i discordi in un pulviscolo individuale e disorganico.

${ }^{13}$ Por isso o Estado é, também, "integral” (GRAMSCI, 1975, Q6, §155, p. 810; Q17, §51, p. 1.947)
} 
como ambiente tanto do consenso, quanto da coerção. Uma das imagens utilizadas por Gramsci para explicitar essa relação orgânica da qual falamos é o Centauro de Maquiavel, composto pela parte férica (coerção) e humana (consenso), é o que demonstra Bianchi (2008) em:

A imagem do Centauro é forte e serve para destacar a unidade orgânica entre a coerção e o consenso. É possível separar a metade fera da metade homem sem que ocorra a morte do Centauro? É possível separar a condição de existência do poder político de sua condição de legitimidade? É possível haver coerção sem consenso? Mas tais questões podem induzir a um erro. Nessa concepção unitária, que era de Maquiavel, mas também de Gramsci, não é apenas a coerção que não pode existir sem o consenso. Também o consenso não pode existir sem a coerção. (p. 190)

Passamos então para a semelhança entre as ideias de Gramsci e as ideias de Nye. Fica clara a ligação entre os componentes da visão gramsciana de hegemonia, a "coerção" e o "consenso", e as duas faces do poder do autor estadunidense, o "poder brando" e o "poder duro". A literatura sobre o tema nos oferece uma série de autores que reconhecem tal semelhança, porém em graus distintos. Os primeiros autores aqui retratados adotam a postura de demonstrar somente que os conceitos de Nye não são originais, apontando a anterioridade de Gramsci. É o caso de Ferreira (2016) e sua análise do poder brando enquanto conceito-chave na avaliação da política externa estadunidense, que aponta:

Não obstante, apesar do seu pioneirismo nas análises das relações internacionais, a ideia central que gira em torno desse conceito [poder brando] não é nova na ciência política. Antonio Gramsci, ao discorrer sobre a noção de hegemonia, explicou que esta se exerce pela combinação da força e do consenso, "sem que a força suplante em muito o consenso, mas, ao contrário, tentando fazer com que a força pareça apoiada no consenso da maioria (...)". (GRAMSCI, 2000, p. 95). O próprio Nye afirma que a ideal de se determinar o arcabouço do debate político já tinha sido discutida anteriormente por Gramsci. (p. 5)

Manifesta-se em termos semelhantes Mercer (2013) ao chamar a atenção para a necessidade de um retorno à Gramsci e sua forma de abordar a cultura, afirmando que a pertinência desse retorno se justifica justamente no momento em que o conceito de poder brando - símile de Gramsci - está em auge. De modo semelhante, também Li e Hong (2012) evidenciam o poder brando como uma das "palavras-chave" dos anos recentes, mas destacam que tal conceito não é absolutamente novo, evidenciando que há meio século antes de Nye, Gramsci já se debruçava sobre a questão da cultura (um dos componentes do poder brando) ao tratar da hegemonia. 
Há também entre os comentadores uma segunda postura, que procura demonstrar não apenas a anterioridade das ideias de Gramsci em relação à Nye, mas também que tais ideias serviram em realidade de substrato teórico e exerceram influência direta na sistemática de poder do autor estadunidense. É o que propõe Eustáquio (201-?) em texto que procura avaliar a teoria gramsciana como fonte da teoria do poder brando, no qual encontramos que:

se nos afigura fundamental para o processo de indagação das fontes da teoria do soft power: a leitura crítica do materialismo marxista feita pelo filósofo político italiano Antonio Gramsci (1891-1937) consubstanciada na teoria da hegemonia, que retoma e aprofunda algumas linhas do pensamento de Lenine (187-1924). (p. 2)

Todavia, é em Zharan e Ramos (2006) que encontramos texto de maior envergadura metodológica e teórica a respeito da influência do pensamento de Gramsci em Nye. O trabalho aqui apresentado coaduna-se com muitas das proposições realizadas pelos autores, principalmente no que tange à afirmação de que a relação das ideias de Nye com Gramsci se deu a partir da leitura empreendida por Nye do teórico canadense Robert Cox (idem, p. 03).

$\mathrm{O}$ argumento dos dois autores consiste em demonstrar que o conceito de poder brando e o conceito gramsciano de hegemonia referem-se igualmente aos mesmos preceitos, isto é, "a um conjunto de princípios gerais, idéias, valores ou instituições; compartilhados, consentidos ou considerados legítimos por diferentes grupos; mas que ao mesmo tempo são recursos de poder, influência ou controle de um grupo sobre outro" (Idem, p. 6). Zharan e Ramos destacam também a relutância de Nye em discutir ou afirmar explicitamente a influência do autor italiano em seu pensamento, fato que é evidenciado pela ausência de debate no livro de Nye sobre o poder brando, Bound to Lead (1990), com os autores gramscianos ou neogramscianos na discussão sobre hegemonias e transições de poder justamente no período histórico onde tais autores ampliam a discussão sobre tais conceitos (ZAHRAN \& RAMOS, 2006, pp. 03-04).

Em síntese, concluo essa seção apontando também para as relações entre as proposições de Nye e o pensamento de Gramsci, passando pela categoria de hegemonia deste último e por outros autores que também possuem tal compreensão (mesmo que em graus distintos). Na próxima seção e a partir das relações aqui 
destacadas, lanço mão de alguns comentários críticos sobre pontos metodológicos e epistemológicos de Nye.

\section{Críticas metodológicas às proposições de Nye}

Começando com os pontos metodológicos, a partir da argumentação que leva em conta a relação de influência da obra de Gramsci em Nye aponto para uma apropriação incompleta do primeiro pelo segundo, isto significa dizer que o autor estadunidense ao tratar da questão do poder e, principalmente, do poder brando, não consegue propor um conceito que dê conta da análise da realidade como o conceito gramsciano o faz, partindo do nexo orgânico entre uma categoria e seu contraponto, como no caso da coerção e do consenso. Tal constatação leva em consideração a separação que o autor de "Soft Power" faz do poder em duas faces, da falta de teorização a respeito da tangibilidade dos recursos de poder (ZAHRAN \& RAMOS, 2006; 2010) e da própria tradição de pensamento na qual o autor se insere. Avançaremos na discussão desses pontos a seguir.

A respeito da primeira constatação, destaco em Nye uma tentativa de estabelecer uma separação entre as faces do poder, dividindo-o em poder duro, relacionado aos modos mais tradicionais de emprego, como a força militar e as constrições econômicas, e em poder brando, relacionado com habilidades de persuasão, atração e aquiescência. Apesar da ampla utilização do conceito de "poder brando" no campo de estudos das Relações Internacionais, levando a uma certa cristalização do mesmo na disciplina, aferimos junto com outros comentadores (ZAHRAN \& RAMOS, 2010), que muitas vezes o sistema de poder desenhado por Nye manifesta-se ambíguo e vago.

A própria proposta metodológica do autor de preconizar uma análise atenta à face comportamental da manifestação do poder e não somente às fontes de poder, carece de ferramentas que auxiliem esse objetivo, isto é, Nye não nos fornece nenhuma ferramenta metodológica ou teórica que permita discernir um comportamento de poder duro e um comportamento de poder brando, pelo contrário, o autor reserva-se apenas em exemplificar historicamente suas proposições (Idem). Isso implica que não há, a partir do esquema teórico desenvolvido por Nye, uma 
possibilidade de estabelecer metodologicamente o poder duro e o poder brando dentro de uma análise a não ser pela submissão dos casos reais à aproximação dos exemplos utilizados pelo autor, buscando encontrar similaridades.

Além disso, a vagueza e ambiguidade das definições de Nye corroboram para tornar uma análise empírica mais difícil. Ao afirmar que as fontes de poder duro e as fontes de poder brando não se relacionam perfeitamente ao comportamento de poder duro e ao comportamento de poder brando, o autor confunde ainda mais seu esquema de poder. A separação anteriormente empreendida não encontra manifestação concreta na realidade, isto é, ainda que a separação sirva a um propósito metodológico, o uso do conceito depende de critérios bastante subjetivos.

A questão da intangibilidade também cumpre a função de abrir mais lacunas não preenchidas. Zahran e Ramos (2006; 2010) demonstram em seus artigos que Nye opta por não estabelecer a definição do que entende por tangibilidade em suas obras (lançando mão apenas de exemplos, como de costume). Essa opção acaba por ampliar as imprecisões dos conceitos de poder brando e poder duro, uma vez que Nye intenta associar o poder duro aos recursos tangíveis e o poder brando aos recursos intangíveis, sem demonstrar o que compreende por tangibilidade (Idem).

Outro ponto também se torna importante: a questão da dependência ou não de um poder sobre o outro. Zahram e Ramos (Idem) apontam mais uma vez que essa forma de argumentação implica que a obra do autor não é capaz de minimizar o problema central: em todos os exemplos, a necessidade do poder duro ou dos recursos de poder duro estão presentes. Tal fato significa uma grande dificuldade na própria utilização autônoma do poder brando, isto é, coloca-se em questão, ao discernir que as lacunas do autor apontam para uma dependência do poder brando ante o poder duro, a própria efetividade do poder brando e sua possibilidade de emprego.

Observamos que tal problema descende da relação de independência entre poder duro e poder brando e que tal relação não condiz com a caracterização de um dos teóricos que - como já afirmei anteriormente - influenciaram o pensamento de Nye, o comunista sardo Antonio Gramsci. A crítica amplia-se nesse momento, pois perpassa a própria consideração de "poder" levada em conta pelas tradições de 
pensamento presentes nos textos de Nye e a discussão gramsciana que extrapola 0 nível de tais proposições- o mainstream teórico dentro das Relações Internacionais.

Aponto que a riqueza do texto gramsciano permite-nos pensar as questões que envolvem o "poder" em relação com: a) as categorias de hegemonia; b) o desenvolvimento desigual e combinado da economia capitalista global (MORTON, 2007; 2011). Isto implica dizer que o "poder" preconizado por Nye não é algo homogêneo dentro do próprio Estado e tampouco pode ser aplicado de modo indistinto nas diferentes sociedades e nos diferentes ambientes dentro das sociedades.

Isso porque, em primeiro lugar, o poder não é somente o "poder do Estado" e não se dá na relação entre dois entes abstratos (Estados, monolíticos, racionais). Essa é uma visão liberal na qual "O Estado é concebido como uma coisa em si, como um absoluto racional" (GRAMSCI, Q1§150, p. 133, tradução livre) ${ }^{14}$. Ao invés disso, manifesta-se dentro de um Estado - sociedade política em união-distinção com a sociedade civil - no qual o "momento de hegemonia" aparece como um processo dinâmico "constantemente construído e constantemente contestado através de diferentes formas de luta de classes e iniciativas contra hegemônicas" (MORTON, 2007, p. 78, tradução livre).

No segundo ponto, recupero um excerto no qual Gramsci fala sobre o papel dos intelectuais na reificação do Estado enquanto absoluto racional em casos nos quais:

o impulso do progresso não está intimamente ligado a um amplo desenvolvimento econômico local que vem artificialmente limitado e reprimido, mas é um reflexo do desenvolvimento internacional que envia à periferia suas correntes ideológicas, nascidas na base do desenvolvimento produtivo dos países mais avançados (GRAMSCI, 1975, Q10II §61, p. 1360, tradução livre $)^{15}$

De onde depreendemos que a questão perpassa também o caráter do desenvolvimento desigual e combinado do capitalismo, no qual o nacional é também influenciado pelo internacional. Isto é, Gramsci possui uma "aguda percepção da

\footnotetext{
${ }^{14}$ Original: Lo Stato è concepito come una cosa a sé, come un assoluto razionale.

${ }^{15}$ Original: la spinta del progresso non è strettamente legata a un vasto sviluppo economico locale che viene artificiosamente limitato e represso, ma è il riflesso dello sviluppo internazionale che manda alla periferia le sue correnti ideologiche, nate sulla base dello sviluppo produttivo dei paesi più progrediti
} 
dimensão supranacional dos problemas" (LIGUORI, 2007, p. 68-70), mas isso não implica num cosmopolitismo - como observável em Croce - pois compreende a dimensão nacional da hegemonia; a proposta de Gramsci pensava os problemas em âmbito internacional, mas sem esquecer do necessário intermediário nacional ${ }^{16}$. 0 conceito de poder de Nye não consegue dar conta de ambas as dinâmicas presentes na leitura do autor italiano. O estadunidense exorta um poder brando, abstrato, reificado.

A partir do exposto, aponto que as proposições de Nye consistem numa apropriação equivocada das categorias de Gramsci, ao tentar separar o poder duro (coerção) do poder brando (consenso) e colocar o peso de sua análise numa exortação do poder brando e de sua importância na política internacional. A ênfase demasiada nos aspectos que numa visão gramsciana fazem parte de um consenso, leva a incompreensão da realidade em termos orgânicos: a hegemonia carrega dentro de si a coerção e o consenso, a separação entre ambos é possível apenas metodologicamente e não organicamente. Isso nos leva a concluir que "Na medida em que ignora a hegemonia, Nye cria a ilusão de um aspecto de poder brando que poderia existir em si apenas pelo consenso, ignorando a realidade social permeada por mecanismos intrínsecos de coerção." (ZAHRAN \& RAMOS, 2006, p. 22).

Cabe questionar, qual a intenção do autor em promover tal separação que, como a argumentação até aqui demonstrou, não é observável na realidade? As leituras de Nye posicionam-se a partir da perspectiva estadunidense, buscando assegurar a liderança global desse país. Nesse sentido, ao avançar o conceito de poder brando, Nye aponta direções para a continuidade de uma hegemonia internacional (termo não usado pelo autor) dos próprios EUA num contexto de custos crescentes para o emprego da força tradicional. O poder brando, a face consensual do poder, seria a chave para uma ação internacional inteligente, com custos relativamente menores. Nye procura assim influenciar não somente a

\footnotetext{
${ }^{16}$ As análises do autor sobre o Risorgimento, a política externa italiana de sua época marcada pelo fascismo e da ascensão estadunidense (plasmada no célebre Caderno 22) demonstram claramente essa "perspectiva internacional" de Gramsci (MORTON, 2007) ou sua "aguda percepção da dimensão supranacional dos problemas" (LIGUORI, 2007, p. 69). Em semelhante diapasão, gostaria ainda de remeter ao Q14 §68 (GRAMSCI, 1975, p. 1729) no qual se lê: "Certo que o desenvolvimento é em direção ao internacionalismo, mas o ponto de partida é 'nacional', e é deste ponto de partida que se deve avançar. Mas a perspectiva é internacional e não pode deixar de ser tal".
} 
diplomacia de seu país, mas também a própria sociedade estadunidense, exortando a importância do poder brando.

Observamos, sintetizando a crítica até aqui, que o autor estadunidense incorre em falhas ao: a) negar a relação de indissociabilidade e dependência da coerção e do consenso; b) perder de vista a complexidade da constituição do Estado em Gramsci; c) não atentar para o fato do desenvolvimento desigual e combinado da economia capitalista a nível global que engendra uma visão de poder em relação com suas temporalidades.

Proponho que a incompreensão de Nye das categorias gramscianas que culminaram nas imprecisões e lacunas metodológicas dentro da esquemática poder brando/poder duro derivam, em certa medida, do próprio contato do autor estadunidense com a obra de Gramsci por meio, de um lado, da deturpação que a obra do comunista sardo sofreu ao longo dos $\operatorname{anos}^{17} \mathrm{e}$, por outro, das apreensões de Cox sobre esse.

No que se refere ao primeiro caso, Morton (2007) aponta as inúmeras tentativas de moldar as proposições gramscianas de acordo com os interesses de determinada época ou grupo, assim temos Gramsci como "caminho italiano do socialismo", como "Leninista Italiano"; Gramsci como um pós-leninista a fim sustentar a ideia eurocomunista das décadas de 1970 e 1980; Gramsci como um pós-comunista a partir de 1990 e, até mesmo, um Gramsci liberal, com ênfase nas questões culturais por meio de um afastamento de seus escritos e a tradição do materialismo histórico (MORTON, 2007, p. 80). Implicando que "Essa redução de Gramsci a outra(s) matriz(es) de 'verdade', conduziu à negação da sua originalidade teórica" (DIAS et al, 1996, p. 106)

\footnotetext{
${ }^{17}$ Para uma crítica das formas de deturpação dos escritos gramscianos ao longo dos anos ver o capítulo "Sobre a leitura dos textos gramscianos: usos e abusos" in: DIAS, E.F. et al, 1996, pp. 105122. Muitas das deturpações da obra do sardo devem-se à edições temáticas dos Quaderni no qual o texto gramsciano é apresentado ao leitor sincronicamente, como uma obra acabada, que versa sobre temas específicos em cada volume. Nesse sentido assume grande importância a Edição Crítica dos Cadernos do Cárcere, editada por Gerratana em 1975 (GRAMSCI, 1975) que compreende a totalidade dos textos do período carcerário, divididos em textos $\mathrm{A}$ (primeira redação), textos $\mathrm{C}$ (segunda redação) e B (única redação). A edição crítica é crucial para o estudo diacrônico de Gramsci, compreendendo que sua obra é um projeto de pesquisa não finalizado que deve ser avaliado em seu movimento interno.
} 
Quanto ao segundo ponto, tal argumento se apoia, de um lado, na afirmação de Zahran e Ramos (2006, p. 03) de que Nye entrou em contato com Gramsci por meio de Cox e, por outro lado, nas proposições de Passos (2015) que sustentam haver mais pontos de distanciamento do que de aproximação entre os escritos de Cox e uma interpretação mais acurada de Gramsci. Para Passos o canadense propositor da "Teoria Crítica" no campo das Relações Internacionais incorre em falhas interpretativas no trato da obra gramsciana. Tais falhas marcam a diferença entre a perspectiva gramsciana e a perspectiva adotada por Cox e se referem:

a) a desconsideração explícita da sua [Cox] filiação à teoria crítica de Horkheimer e a justaposição com categorias de Gramsci, portador de um estatuto epistemológico diferente daquele do filósofo alemão; b) a diferenciação entre as distintas temporalidades de nacional e internacional na visão gramsciana e o caráter transnacional de vários fenômenos na acepção coxiana; c) o caráter da sociedade civil e do bloco histórico na perspectiva da Gramsci e seu caráter generalizadamente transnacional na acepção coxiana; d) a aproximação de forma indireta entre Cox e a leitura hegemônica do PCI na apropriação do pensamento de Gramsci; e) o caráter eclético subjacente à concepção histórica coxiana por oposição ao historicismo absoluto gramsciano fundado em perspectiva da autossuficiência do materialismo histórico. (PASSOS, 2015)

Para além dessa questão, cabe destacar que Cox possui sua formação intelectual dentro do campo das Relações Internacionais, cujo qual impera o paradigma estadocêntrico que de todo modo não é aquele utilizado por Gramsci ${ }^{18}$. Desse modo, sugiro que o contato realizado por Nye com a obra gramsciana por meio de Cox incorreu em vulgarizações das proposições originais do autor sardo, que se manifestam nas imprecisões metodológicas na definição dos conceitos de "poder brando" e "poder duro".

Visto isso, lanço mão de argumento a ser melhor desenvolvido em posteriores momentos. A discussão de Gramsci é muito mais ampla do que a

\footnotetext{
${ }^{18}$ A interpretação de Passos (2015) nesse ponto é crucial: "O fato de Cox formular uma proposição contra-hegemônica focada em um perfil terceiromundista de Estados como alternativa aos Estados Unidos em uma de suas primeiras reflexões sobre a teoria crítica (COX, 1981: pp. 151-152) levanta mais uma aproximação eventual com o realismo e não a sua superação. Explique-se: a perspectiva alternativa em termos de uma hegemonia alternativa no registro gramsciano não seria estadocêntrica, mas sim focada nos grupos e classes subalternas". Em outro texto (PASSOS, 2016) o autor especifica como a análise de Cox deixa de contemplar pontos cruciais da obra gramsciana, a começar pelo nexo orgânico entre sociedade civil-Estado, crucial para uma reflexão sobre uma possível "sociedade civil internacional" - que, ademais, não encontra respaldo no texto gramsciano. Para além disso, aponta também que Cox corrobora uma visão excessivamente tocquevilliana da sociedade civil em Gramsci (remetendo-nos à famosa - e questionável - interpretação bobbiana do sardo)
} 
discussão tradicional do poder empreendida pelos teóricos "liberais" e "realistas" na disciplina de Relações Internacionais. Seus escritos baseiam-se numa metodologia que permite inserir a discussão dos elementos da ciência política numa análise que os situem:

\begin{abstract}
nos vários níveis da relação de forças, a começar pela relação das forças internacionais (onde se localizariam as notas escritas sobre o que é uma grande potência, sobre os agrupamentos de Estados em sistemas hegemônicos $e$, por conseguinte, sobre o conceito de independência e soberania no que se refere às pequenas e médias potências), passando em seguida às relações objetivas sociais, ou seja, ao grau de desenvolvimento da forças produtivas, às relações de força política e de partido (sistemas hegemônicos no interior do Estado) e às relações políticas imediatas (ou seja, potencialmente militares). (GRAMSCI, 2000, Q13 §2, pp. 19-20).
\end{abstract}

Com o claro objetivo de atuar sobre a realidade. É a questão colocada por Gramsci - e perdida de vista pela tradição liberal de Nye - sobre a relação entre o internacional $e$ as relações sociais fundamentais, no qual 0 internacional "indubitavelmente segue" as relações sociais fundamentais, mas "reage passiva e ativamente sobre as relações políticas (de hegemonia dos partidos)" (GRAMSCI, 2000, Q 13, §2, p. 20). O referencial gramsciano ultrapassa o Estado e aponta na direção das classes sociais e grupos subalternos, na busca da "unificação de todo o gênero humano".

Notavelmente, uma proposta metodológica de maior envergadura, onde o principal objetivo é estabelecer uma análise capaz de "justificar uma atividade prática, uma iniciativa de vontade" (GRAMSCI, 2000, Q13, §17, p. 45). Assim a "análise das relações de força" abrange a questão do desenvolvimento desigual e combinado ao conceber que "estas relações internas de um Estado-Nação entrelaçam-se com as relações internacionais, criando novas combinações originais e historicamente concretas." (GRAMSCI, 2000, Q13 §17, p. 42) E a análise aprofunda-se, uma vez que mesmo dentro do lócus de um Estado-Nação em específico existem "várias seções territoriais com estruturas diferentes e diferentes relações de força em todos os graus" (idem), como os escritos de "Alcuni temi della quistione meridionale" demonstram.

Chegamos, assim, ao último momento de crítica, de caráter epistemológico. Como observei acima, a proposta de Gramsci e de seu marxismo, a filosofia da práxis, é de crítica radical da realidade, com o objetivo claro de atuar sobre a 
mesma, de transformá-la. Falamos do nexo central e indissolúvel entre teoria e prática. Uma vez que é justamente a ação que garante o critério de racionalidade de uma filosofia (Q10/II §2, §17), a filosofia acompanha a própria história (Q11 §14), deve se fazer história (Q11 §12). A filosofia da práxis é, portanto, criadora (Q11 $\S 59)$, pois atua sobre a realidade, mudando-a. Sua função é a de construir uma nova concepção de mundo, tendo por base o necessário contato com os simples, elevando-os a um nível cultural superior (Q11 §12.IV) ${ }^{19}$. É, na verdade, inconcebível sem a clara conexão com a realidade (Q11 §37). "A identificação de teoria e prática é um ato crítico, pelo qual a prática vem demonstrada racional e necessária ou a teoria realística e racional" (GRAMSCI, 1975, Q15 §22, p. 1.780, trad. livre) ${ }^{20}$.

Toda essa visão remete à concepção historicista de Gramsci, no qual a filosofia não passa de mera elucubração mental se não é capaz de envolver-se às massas, de atuar sobre a vontade, servindo à ação. Falamos da união entre a filosofia, a história e a política. Princípio que define sua própria visão de "ortodoxia" para a filosofia da práxis, que se pauta:

no conceito fundamental que a filosofia da práxis "basta a si mesma", contém em si todos os elementos fundamentais para construir uma total e integral concepção de mundo, uma total filosofa e teoria das ciências naturais, e não só, mas também por dar vida a um integral organização prática da sociedade, isto é, para tornar-se uma civilização total e integral (GRAMSCI, 1975, Q11 §27, p. 1.434, trad. livre, negrito meu) ${ }^{21}$

Posição diametralmente oposta daquela de Nye, cuja visão de ciência tem por referência critérios oriundos das ciências naturais, aproximando-o de uma posição positivista. Isto é, sua teoria não propõe a atuar sobre a sociedade, restringindo-se aos critérios de interpretação e análise da mesma. É o sentido da

\footnotetext{
${ }^{19}$ A propósito, cabe destacar: "A posição da filosofia da práxis é antitética a esta católica [separação entre intelectuais e massa]: a filosofia da práxis não tende a manter os "simples" em sua filosofia primitiva de senso comum, mas sim levá-los a uma concepção superior da vida. Se ela afirma que a necessidade de contato entre intelectuais e simples, não é para limitar a atividade científica e manter uma unidade no baixo nível das massas, mas para construir um bloco intelectual-moral que torne politicamente possível um progresso intelectual da massa e não apenas de escassos grupos intelectuais." (GRAMSCI, 1975, Q11, §12, pp. 1384-1385, trad. livre)

${ }^{20}$ No original: "L'identificazione di teoria e pratica è un atto critico, per cui la pratica viene dimostrata razionale e necessaria o la teoria realistica e razionale."

${ }^{21}$ No original: "nel concetto fondamentale che la filosofia della praxis «basta a se stessa», contiene in sé tutti gli elementi fondamentali per costruire una totale ed integrale concezione del mondo, una totale filosofia e teoria delle scienze naturali, non solo, ma anche per vivificare una integrale organizzazione pratica della società, cioè per diventare una totale, integrale civiltà."
} 
afirmação a seguir, encontrada em Power and Interdependence, livro que alçou o autor dentro do campo das RRII:

Nossa tarefa neste livro não é discutir a posição modernista ou tradicionalista. Visto que nossa era é marcada por continuidade e mudança, isso seria infrutífero. Em vez disso, nossa tarefa é fornecer um meio de destilar e misturar a sabedoria em ambas as posições desenvolvendo um quadro teórico coerente de análise política da interdependência. Devemos desenvolver vários modelos diferentes, mas potencialmente complementares, ou ferramentas intelectuais, para compreender a realidade da interdependência na política mundial contemporânea. Igualmente importante, devemos tentar explorar as condições em que cada modelo provavelmente produzirá previsões precisas e explicações satisfatórias. A política mundial contemporânea não é uma rede perfeita; é uma tapeçaria de diversos relacionamentos. Em tal mundo, um modelo não pode explicar todas as situações. O segredo da compreensão reside em saber qual abordagem ou combinação de abordagens usar na análise de uma situação (KEOHANE, NYE Jr, 2012, p. 04, trad. livre, negritos meus)

Isto é, a teoria tem por função "compreender a realidade", "produzir previsões precisas" e "explicações satisfatórias", combinando modelos para "analisar uma situação". Não há menção a nenhum papel de crítica radical tal como em Gramsci. O tom é de conservação do status quo, uma vez que se deseja apenas explicar a realidade e, no máximo, fornecer predições sobre alguns acontecimentos $^{22}$. Sua teoria auxilia a conhecer melhor o terreno de ação, sem alterar seus condicionantes. Bound to Lead, inclusive, foi escrito com o objetivo de "compreender a mudança na política mundial", nascendo de um projeto que tinha uma vertente devotada à "compreensão das condições de longo termo para a estabilidade internacional” (NYE Jr, 1990, p. xviii, trad. livre). Nye oferece, portanto, uma aguda interpretação da mudança da natureza do poder em sua época, lançando advertências sobre como deve ser a ação estadunidense nesse novo contexto.

\footnotetext{
${ }^{22}$ Sobre as predições, cabe apontar certa relativização efetivada pelos autores no Prefácio à $4^{a}$ edição da obra, todavia, as conexões com a perspectiva positivista de teoria permanecem, como os trechos destacados permitem concluir: "Power and Interdependence nunca pretendeu fazer previsões sobre o futuro ou fornecer uma metodologia para fazê-lo. Em vez disso, ele foi projetado para fornecer conceitos que ajudassem os observadores da política mundial a entender e interpretar o que eles viam, para que eles pudessem ajustá-lo a alguns padrões gerais e não se surpreender com os desenvolvimentos que de fato surpreenderiam aqueles com o panorama de segurança estatista, anteriormente proposto pela teoria política "realista". O teste da validade deste quadro, portanto, não é se ele previu esses eventos ou teria levado seus praticantes a fazê-lo (ele não fez), mas se nos ajuda a entender suas ramificações: as "ondas de choque", para assim falar, que reverberam após os eventos." (KEOHANE, NYE Jr, 2012, p. xxviii, trad. livre, negritos meus)
} 
Aponto, em síntese, que as lacunas conceituais acima apresentadas demonstram que o esquema de poder desenhado por Nye em 1990 e aperfeiçoado ao longo dos anos não consegue fornecer um painel teórico e metodológico completo. Além disso, constatamos - apesar da necessidade de maior aprofundamento da pesquisa - que a discussão empreendida pelo teórico do poder brando sobre a temática do "poder" insere-se numa das tradições de pensamento hegemônica dentro das Relações Internacionais. Inferi, portanto, de que modo as proposições gramscianas, atentas à dinâmicas não compreendidas pelos conceitos estáticos da tradição de pensamento de Nye, abrem espaço para discussões mais profundas, de modo a apresentar uma postura crítica, trazendo consigo uma visão do Estado que aponta para os embates entre suas coletividades internas e para a questão do desenvolvimento desigual e combinado da economia capitalista centrado nas classes e grupos subalternos.

\section{Considerações finais}

Após o discutido farei nessa seção algumas considerações parciais obtidas com o atual andamento da pesquisa. É importante reiterar mais uma vez a semelhança e a influência da categoria gramsciana dentro do pensamento do autor estadunidense. Os conceitos preconizados por Nye já integravam, de certo modo, a noção de hegemonia de Gramsci. A divisão arbitrária e sem respaldo metodológico entre o poder brando e o poder duro - as partes do centauro - implica em falhas que requerem do leitor/estudioso um uso de aproximações aos exemplos oferecidos por Nye em seus livros a fim de discernir entre um comportamento e outro. Isto é, os critérios de distinção entre poder duro e poder brando, por mais que possuam um propósito metodológico dentro da obra de Nye, são bastantes subjetivos.

Além disso, a discussão realizada sobre as bases epistemológicas dos dois autores permite apontar: se o empreendimento de Gramsci com a categoria de hegemonia dá-se num claro tom de agir sobre a realidade, isto é, com o objetivo de promover uma radical alteração, de unificar todo o gênero humano, por permitir compreender aquilo que Liguori denominou esfera do "pré-intencional", dos condicionantes ideológicos prévios à formação do sujeito (coletivo) e da vontade 
(coletiva) abrindo possibilidades de ação sobre tais condicionantes (LIGUORI, 2007, pp. 77-136); a postura de Nye é de um intelectual orgânico à classe dirigente (burguesa), sua amputação da teoria gramsciana trata de uma tentativa de mobilizar as questões presentes na teoria da hegemonia a partir de uma visão positivista e reificadora da realidade, nitidamente conservadora, uma vez que advoga a ciência não em relação de ação sobre a realidade, mas em simples posição de explicação, de compreensão e, se com sucesso, de sua "previsão".

Resumindo, se a proposta teórica de Gramsci é de uma crítica radical da realidade e extrapolável - dadas as devidas precauções metodológicas que a categoria de "tradução" enseja - também para o campo das Relações Internacionais; a proposta teórica de Nye não passa de uma (outra) forma de avaliar a realidade a fim de compreendê-la, promovendo uma conservação do status quo e, consequentemente, da dominação burguesa.

Enfim, a crítica deve ser expandida para o próprio modo tradicional de pensar as Relações Internacionais em momento oportuno. Procurei demonstrar que a obra gramsciana contribui em muito para aprofundar o nível de análise desse campo de estudos, concebendo formulações e propostas metodológicas que escapam às concepções abstratas do "Estado" e do "poder" comumente utilizadas.

\section{Referências Bibliográficas}

BIANCHI, Alvaro. O laboratório de Gramsci: filosofia, história, política. São Paulo: Alameda, 2008.

CALLEGARI, André Rossi. Brasil e "Soft power" :capacidades e evolução do poder brando brasileiro de FHC à Lula. 2011. 43 f. Monografia (Graduação Relações Internacionais). Faculdade de Ciências Humanas e Sociais, UNESP, Franca.

DIAS, Edmundo Fernandes et al. O Outro Gramsci. São Paulo: Editora Xamã, 1996.

EUSTÁQUIO, Victor. Notas sobre a problemática do poder: O paradigma gramsciano como fonte da teoria do soft power. [201-?]. Disponível em: $<$ https://www.academia.edu/3511802/O paradigma gramsciano como fonte do so ft power>. Acesso em: 15 de abr de 2016.

FERREIRA, Marcos A. F. S. Definições conceituais para o entendimento de Política Externa: o poder duro e o poder brando, por Marcos Alan Ferreira. Mundorama - Revista de Divulgação 
Científica em Relações Internacionais. Disponível em: $<$ https://www.mundorama.net/?article=definicoes-conceituais-para-o-entendimento-de-politicaexterna-o-poder-duro-hard-power-e-o-poder-brando-soft-power-por-marcos-alan-s-v-ferreira> . Acesso em 18 de mai de 2016

GILL, Bates; HUANG, Yanzhong. Sources and limits of Chinese 'soft power'. Survival, v. 48, n. 2, pp. 17-36.

GOUVEIA, Grazielle Roberta Desiderio. A indústria cervejeira como instrumento de soft power. 2015. 39 f. Monografia (Graduação Relações Internacionais). Faculdade de Ciências Humanas e Sociais, UNESP, Franca.

GRAMSCI, Antonio. Cadernos do Cárcere, volume 3. Trad: Carlos Nelson Coutinho. Rio de Janeiro: Civilização Brasileira, 2000.

Quaderni del carcere, Torino: Einaudi, 1975.

HAYNES, Jefrey. Religious Transnational Actors and Soft Power. Nova lorque: Routledge, 2016.

KEOHANE, Robert O \& Joseph S. Nye Jr. Power and Interdependence in the information age. Foreign Affairs, v. 77, n. 5, pp. 81-94, 1998.

KEOHANE, Robert O.; NYE, Joseph S. Jr. Power and interdependence. 4a. ed. Nova lorque: Longman, 2012.

KURLANTZICK, Joshua. Charm Offensive: How China's Soft Power is Transforming the World. Yale: Yale University Press, 2007.

LI, Lin \& HONG, Xiaonan. The Application and Revelation of Joseph Nye's Soft Power Theory. Studies in Sociology of Science, vol 3, nํ2, 2012, pp. 48-52.

LIGUORI, Guido. Roteiros para Gramsci. Trad: Luiz Sérgio Henriques. Rio de Janeiro: Editora UFRJ, 2007.

LO PRETE, Mariana Navas. Disney e soft power: uma análise da atuação da empresa no sistema internacional através da cultura de massa. 2016. $63 \mathrm{f}$. Monografia (Graduação Relações Internacionais). Faculdade de Filosofia e Ciências de Marília, UNESP, Marília.

MANZENREITER, Wolfram. The Beijing Games in the Western Imagination of China: The Weak Power of Soft Power. Journal of Sport and Social Issues, v. 34, n. 1, pp. 29-48.

MARTEL, Frédéric. Mainstream: a guerra global das mídias e das culturas. Editora José Olympio, 2013.

MARTINS, Rafael Vieira. O jazz como instrumento de soft power norte-americano no Brasil no segundo terço do século XX. 2016. 49 f. Monografia (Graduação Relações Internacionais). Faculdade de Ciências Humanas e Sociais, UNESP, Franca. 
MELISSEN, Jan (org.). The New Public Diplomacy: Soft Power in International Relations. Houdmills (UK): Palgrave Mcmillan, 2005.

MERCER, Collin. Antonio Gramsci and 'soft power': e-laborare or the work and government of culture. 2013.2 Disponível em: <http://www.academia.edu/3703420/Antonio Gramsci and soft power elaborare or the work and government of culture>. Acesso em 22 de abr de 2016.

MIRANDA, Marina Pimentel. O K-Pop como mecanismo de soft power sul-coreano no Ocidente. 2016. 37 f. Monografia (Graduação Relações Internacionais). Faculdade de Ciências Humanas e Sociais, UNESP, Franca.

MORGENTHAU. Hans. A Política entre as Nações. São Paulo: Editora UnB, 2003.

MORTON, Adam David. Revolution and state in modern Mexico: the political economy of uneven development. Plymouth: Rowman \& Littlefield Publishers, 2011.

Political Economy. Londres: Pluto Press, 2007.

. Unravelling Gramsci: Hegemony and Passive Revolution in the Global

NYE Jr, Joseph S Jr. Bound to Lead: the Changing Nature of American Power. New York: Basic Books, 1990.

. Cyber Power. Cambridge: Harvard Kennedy School, 2010.

. Is the American Century Over? Malden: Polity, 2015.

. O futuro do poder. São Paulo: Benvirá, 2012.

. Softpower: the means to success in World Politics. New York: PublicAffairs, 2004.

. The future of power. New York: Public Affairs, 2011.

. The Paradox of American Power: why the world's only superpower can't go it alone. New York: Oxford University Press, 2002.

. Think Again: Soft Power. Foreign Policy, 2006. Disponível em: <http://www.foreignpolicy.com/articles/2006/02/22/think again soft power>. Acesso em: 30 mar 2015.

PASSOS, Rodrigo Duarte Fernandes dos. Cox e a teoria crítica das relações internacionais: ecletismo ou coerência? Relatório Final de Pesquisa apresentado ao CNPq, mimeo, 2015.

- Marxismo, Estado e Relações Internacionais: Gramsci e Frankfurtianos marxistas versus sua apropriação hegemônica liberal por Robert W. Cox. In: Jornada Internacional de Estudos e Pesquisas em Antonio Gramsci, 1, 2016, Fortaleza/CE. Anais... Fortaleza: Universidade Federal do Ceará, 2016. [ISSN: 2526-6950] 
THOMAS, Peter D. Hegemony, passive revolution and the modern Prince. Thesis Eleven, v. 117, n. 1, pp. 20-39, 2013.

THUSSU, Daya Kishan. Communicating India's Soft Power: Buddha to Bollywood. Nova lorque: Palgrave Macmillan, 2013.

ZAHRAN, Geraldo \& RAMOS, Leonardo. Da hegemonia ao Poder Brando: implicações de uma mudança conceitual. Trabalho apresentado no $30^{\circ}$ Encontro Anual da Associação Nacional de Pós-Graduação e Pesquisa em Ciências Sociais, Caxambu, 2006.

ZAHRAN, Geraldo \& RAMOS, Leonardo. From hegemony to soft power: implication of a conceptual change In: PARMAR, Inderjeet \& COX, Michael (Eds.) Soft Power and US Foreign Policy: theoretical, historical and contemporary perspectives. Abingdon: Routledge, 2010, p. 12-31.

Recebido em 26/09/2017.

Aprovado em 14/11/2017. 